\title{
Veith, Nicola, Hacia el Puerto de la Felicidad. La emigración alemana a Sierra Morena y Andalucía en el siglo XVIII. Sevilla: Fundación Caja Rural Jaén, 2021. ISBN: 978-84-1201-233-0. 395 pp.
}

\author{
FRIEDERIKE OTT \\ https:// orcid.org/0000-0001-8110-1169 \\ z92ototf@uco.es \\ Universidad de Córdoba. https://ror.org/05yc77b46
}

En los últimos años, la bibliografía en torno a la repoblación de Andalucía en el siglo XVIII y a la creación de las Nuevas Poblaciones de Sierra Morena y Andalucía ha ido creciendo de forma constante y continua. Autores como Adolfo Hamer Flores (2009), María Isabel García Cano (2013), José Antonio Fílter Rodríguez (2018) o Francisco Pérez-Schmid Fernández, para mencionar meramente una pequeña muestra de autores de las numerosas publicaciones, han ido dando visibilidad a un acontecimiento histórico que durante muchos años ha permanecido oculto: la creación de las Nuevas Poblaciones a instancias de Carlos III a finales del s. XVIII en Andalucía, en las zonas de Sierra Morena y la campiña cordobesa, con colonos procedentes principalmente de Alemania, Francia y Suiza.

Nicola Veith, con su tesis doctoral, ha aportado un nuevo punto de vista de esta ya amplia bibliografía, realizando un trabajo extenso y exhausto, esta vez desde el punto de vista y de partida de Centroeuropa.

Una síntesis de esta tesis ha sido traducida ahora al castellano por Pilar Castillo Bernal y Robert Szymyślik y publicada por la Fundación de Municipios Pablo de Olavide bajo el título Hacia el Puerto de la Felicidad. La emigración alemana a Sierra Morena y Andalucía en el siglo XVIII.

En esta edición, la autora ha dividido su trabajo en tres grandes bloques, comenzando por los antecedentes de la emigración a España en el S. XVIII, en el que se abarca tanto la situación política-social en las regiones de procedencia de los colonos, el perfil social que tenían estos y la propaganda realizada por parte del contratista Johann C. von Thürriegel para atraer a los nuevos colonos y convencerles de emprender tal aventura.

En el segundo bloque se ocupa de la descripción detallada del viaje y de la llegada de los colonos a las nuevas regiones andaluzas. En ella caben no solo las dificultades encontradas por los colonos para abandonar su patria debido a las restricciones y prohibiciones - no hay que olvidarse de la situación de despoblamiento de Centroeuropa por las diversas grandes guerras y otras 


\section{RESEÑAS}

múltiples adversidades, de los obstáculos al llegar a las zonas de destino por carecer de infraestructuras mínimas como alojamiento, campos por cultivar, etc.

En la última parte, Veith lleva a cabo un análisis exhaustivo de la situación y de las circunstancias en las que se hallaron los colonos una vez comenzaron la fundación y construcciones de las Nuevas Poblaciones, las problemáticas como la situación sanitaria, económica, organización, etc., así como la pérdida de la identidad centroeuropea por la asimilación rápida y casi forzosa a la vida y las circunstancias del país de destino, España.

Veith realiza en este último bloque un gran trabajo de estudio y análisis sobre los distintos datos ya publicados, pero también sobre datos recopilados por ella, como los de procedencia, fallecimiento, matrimonio, nacimientos, etc. En las distintas poblaciones de las Nuevas Poblaciones, facilitando de esta manera un gran trabajo estadístico sobre la composición de estas.

Concluyendo se debe hacer constar que la autora ha realizado un enorme trabajo no solo reuniendo las publicaciones realizadas hasta la actualidad por la comunidad de habla alemana y francesa, sino también recopilando y analizando datos que no habían sido publicados hasta el momento. Por ello, no cabe duda de que esta traducción de la tesis original, defendida en 2018, es una aportación importante en el estudio de las Nuevas Poblaciones de Sierra Morena y Andalucía y que ayudará, sin duda, a entender mejor las dificultades e inconvenientes con los que se encontraron los colonos tanto en el proceso de la emigración desde los países centroeuropeos como en su posterior asentamiento y vida en España.

\section{Referencias bibliográficas}

FÍLTER RODRÍGUEZ, José Antonio, Inmigrantes centroeuropeos en la Andalucía del s. XVIII. Ayuntamientos de Cañada Rosal y La Luisiana-El Campillo, 2018.

GARCía CANO, María Isabel, El gran proyecto ilustrado de Carlos III y Olavide. Las Nuevas Poblaciones de Andalucía: Fuente Palmera (1768-1835). Córdoba: Diputación Provincial, 2013.

HAmer Flores, A. H., Las Nuevas Poblaciones de Andalucía y sus primeros colonos (1768-1771). Bubok, 2009.

OTT, Friederike, La adaptación y traducción de nombres, apellidos y documentos extranjeros durante la colonización de Sierra Morena en el s. XVIII. El caso de Guarromán. Un estudio de corpus y sus aspectos sociolingüísticos. Trabajo de Fin de Máster inédito, Universidad de Córdoba, 2021.

PÉREZ-SCHMID FERNÁNDEZ, Francisco, La Ilustración de Sierra Morena. Disponible en línea en: http://www.lailustraciondesierramorena.es 